\title{
Transition Metal Catalyzed One-Pot Synthesis of Water-Soluble Amphiphilic Molecular Nanocarriers
}

\author{
Guanghui Chen and Zhibin Guan* \\ Department of Chemistry, 516 Rowland Hall, University of California, Irvine, CA 92697-2025
}

\section{Supporting Information}

\section{EXPERIMENTAL SECTION}

\section{Synthesis and characterization of comonomers and copolymers}

General Procedure. The catalyst synthesis and handling were carried out in Vacuum Atmosphere gloves box filled with nitrogen. All other moisture and air-sensitive reactions were carried out in flame-dried glassware using magnetic stirring under argon or nitrogen. Removal of organic solvents was accomplished by rotary evaporation and is referred to as concentrated in vacuo. Flash column chromatography was performed using forced flow on EM Science 230-400 mesh silica gel. NMR spectra were recorded on Bruker DRX400, Bruker GN500, or Bruker Omega500 MHz FT-NMR instruments. Proton and carbon NMR spectra were recorded in ppm and were referenced to indicated solvents. NMR Data was reported as follows: chemical shift, multiplicity ( $\mathrm{s}=$ singlet, $\mathrm{d}=$ doublet, $\mathrm{t}=$ triplet, $\mathrm{q}=$ quartet$)$, coupling constant(s) in Hertz $(\mathrm{Hz})$ and integration. Multiplets $(\mathrm{m})$ were reported over the range (ppm) at which they appear at the 
indicated field strength. Elemental analysis was preformed by Atlantic Microlabs, Norcross, GA. High resolution mass spectra (HR-MS) were recorded on Micromass LCT or Micromass Autospec. Toluene, THF, diethyl ether and dichloromethane and other solvents were purified by passing through solvent purification columns following the method introduced by Grubbs. ${ }^{1}$ Ultrahigh purity (UHP) $\mathrm{N}_{2}$ and ethylene were obtained from Airgas. The palladium bisimine catalyst used in our polymerization was synthesized by following literature report. ${ }^{2,3}$

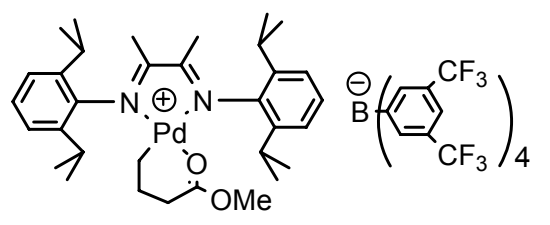

Catalyst 4

\section{Preparation of Comonomer 3.}

\section{Scheme S1}

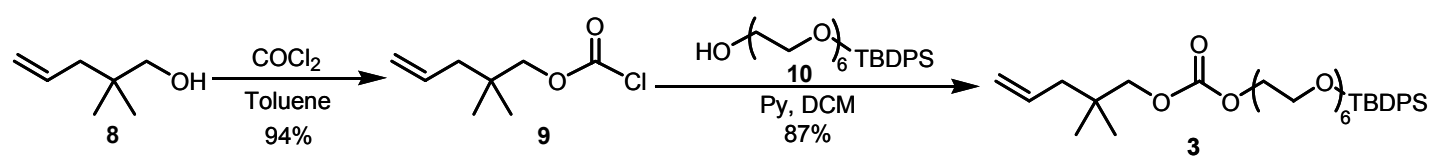

To a solution of 2,2-dimethyl-pent-4-enyl alcohol ${ }^{4}(8,2.28 \mathrm{~g}, 0.02 \mathrm{~mol}, 1.0$ equiv.) in toluene $(10 \mathrm{~mL})$ was added phosgene solution in toluene $(20 \mathrm{wt} \%$ or $1.93 \mathrm{M})(52 \mathrm{~mL}, 0.1 \mathrm{~mol}, 5$ equiv.). The solution was allowed to stir for 24 hours. Solvent and excess phosgene was removed by concentrating in vacuo. Compound 2,2-dimethyl-pent-4-enyl chloroformate, 9, was obtained by drying the mixture under vacuum and used without further purification $(3.32 \mathrm{~g}, 94 \%)$. At $0{ }^{\circ} \mathrm{C}$, a solution of 9 (1.94 g, 0.011 mol, 1.1 equiv.) in $20 \mathrm{~mL}$ DCM was slowly added to a solution of 17-(tert-butyldiphenylsiloxy)-1-hydroxy-3,6,9,12,15-pentaoxyheptadecane, ${ }^{5} \quad \mathbf{1 0}, \quad(4.40 \mathrm{~g}, 0.01$ mol, 1.0 equiv.) and pyridine ( $0.91 \mathrm{~mL}, 0.011 \mathrm{~mol}, 1.1$ equiv. $)$ in $50 \mathrm{~mL}$ DCM. The mixture was then allowed to stir at room temperature overnight. Aqueous solution of $\mathrm{NH}_{4} \mathrm{Cl}$ was added to 
quench the reaction. Aqueous layer was separated and washed with DCM three times. Combined organic layers were washed with brine, dried over $\mathrm{Na}_{2} \mathrm{SO}_{4}$ and concentrated in vacuo. The pure product 3 was obtained in $87 \%$ yield after flash column chromatography (EtOAc in Hex: 0 to 20\%). ${ }^{1} \mathrm{H}$ NMR (500 MHz, $\left.\mathrm{CDCl}_{3}\right): \delta$ 7.68-7.70 (m, 4H), 7.36-7.44 (m, 6H), 5.78-5.86 (m, $\left.1 \mathrm{H}\right)$, 4.99-5.08 (m, 2H), 4.26-4.28 (m, 2H), $3.86(\mathrm{~s}, 2 \mathrm{H}), 3.81\left(\mathrm{dd}, J_{I}=J_{2}=5.4,2 \mathrm{H}\right), 3.60-3.70(\mathrm{~m}, 20 \mathrm{H})$, $2.04(\mathrm{~m}, 2 \mathrm{H}), 1.05(\mathrm{~s}, 9 \mathrm{H}), 0.093(\mathrm{~s}, 6 \mathrm{H}) .{ }^{13} \mathrm{C} \mathrm{NMR}\left(125 \mathrm{MHz}, \mathrm{CDCl}_{3}\right): \delta$ 155.61, 135.78, 134.38, $133.89,129.77,127.80,118.03,75.87,72.61,70.85(\mathrm{~m}), 69.14,67.04,63.61,43.38,34.41,27.00$, 24.12, 19.37. HR-MS: calcd. for $\left[\mathrm{C}_{36} \mathrm{H}_{56} \mathrm{O}_{9} \mathrm{Si}+\mathrm{H}^{+}\right]$: 661.3694, found: 661.3731 .

Comonomer 5 was prepared by following previous report. ${ }^{4}$

General Procedure of Polymerization: Ethylene copolymerization with polar comonomers was performed in a $100 \mathrm{~mL}$ flame dried flask connecting to a bubbler filled with mineral oil. Low ethylene pressure $(0.1 \mathrm{~atm})$ was maintained by slowly bubbling a mixed gas of $90 \% \mathrm{~N}_{2}$ and $10 \%$ ethylene at $1.0 \mathrm{~atm}$. A degassed comonomer solution in chlorobenzene/toluene (1:3, by volume) was added into the flask followed by a degassed catalyst solution in chlorobenzene/toluene (1:3, by volume). After purged the flask for a few minutes with the polymerization gas, the $\mathrm{N}_{2} /$ ethylene gas mixture was bubbled constantly through the polymerization solution. Polymerization was allowed to continue for 24 to 48 hours at room temperature. The rate of the gas mixture flow was kept at about two bubbles per second as indicated by the bubbler. Polymerization was finally quenched by adding excess amount of triethylsilane. The resulting polymer solution was passed through Celite and neutral alumina gel to remove catalyst residue before being concentrated. 
Synthesis of Copolymer 1: The comonomer 3 (3.2 g, $0.0048 \mathrm{~mol}, 0.4 \mathrm{M})$ was copolymerized with ethylene at $0.1 \mathrm{~atm}$ with the catalyst $4(100 \mathrm{mg}, 0.07 \mathrm{mmol})$ for 48 hours. After addition of $\mathrm{Et}_{3} \mathrm{~N} \cdot 3 \mathrm{HF}(0.81 \mathrm{~mL}, 0.005 \mathrm{~mol})$ at the end of polymerization, the solution was allowed to stir at room temperature for an additional 48 hours. The mixture was diluted with large amount of $\mathrm{CHCl}_{3}$, which was washed with brine. The organic layer was separated and concentrated. The residue was then re-dissolved in a small amount of acetone. Pure copolymer $1(0.7 \mathrm{~g})$ was obtained by repetitive precipitation of the polymer from the acetone solution by addition of a mixture of hexanes and ethyl acetate (10:1). ${ }^{1} \mathrm{H}$ NMR (500 MHz, $\left.\mathrm{CDCl}_{3}\right): \delta 4.26(\mathrm{~s}, 2 \mathrm{H}), 3.83(\mathrm{~m}$, 2H), 3.50-3.75 (m, 20H), 2.98 (broad, 1H), 1.02-1.35 (broad, 16.3H), 0.85-0.95 (broad, 7.0H). Comonomer incorporation ratio $(r)$ is determined to be $24 \mathrm{~mol} \%$ by ${ }^{1} \mathrm{H}$ NMR. Molecular weight of hydrophobic core ( $\mathrm{MW}_{\text {core }}$ ) is $\sim 3,000 \mathrm{~g} / \mathrm{mol}$. GPC-MALS (using THF as eluent): $M_{\mathrm{n}}=9,800 \pm$ $40 \mathrm{~g} / \mathrm{mol}, M_{\mathrm{w}}=13,100 \pm 500 \mathrm{~g} / \mathrm{mol}, \mathrm{PDI}=1.3$.

Synthesis of Copolymer 2: Comonomer 5, tert-butyl-(2,2-dimethyl-pent-4-enyloxy)-diphenylsilane $^{4}(12.0 \mathrm{~g}, 0.034 \mathrm{~mol}, 1.0 \mathrm{M})$, was first copolymerized with ethylene at $0.1 \mathrm{~atm}$ with catalyst 4 (100 mg, $0.07 \mathrm{mmol})$ for 48 hours. After quenching the copolymerization, an excess amount of TBAF was added to the polymerization solution, which was allowed to stir at room temperature for an additional 24 hours. The hydroxyl functionalized polyethylene, 6, was obtained by repetitive precipitation of the polymer solution with methanol. It was then dried under vacuum, and re-dissolved in THF as a stock solution. Poly(ethylene glycol) chloroformate ${ }^{6}\left(7,2.4 \mathrm{~g}, 0.003 \mathrm{~mol}, M_{\mathrm{n}}=\sim 814\right)$ was added into the above polymer 6 solution $(30 \mathrm{~mL}, 0.6 \mathrm{~g}$ of $\mathbf{6})$ in the presence of pyridine $(0.24 \mathrm{~mL}, 0.003 \mathrm{~mol})$. The reaction mixture was allowed to stir at room temperature for 24 hours before being diluted with a large volume of $\mathrm{CHCl}_{3}$ and washed 
with brine. The organic layer was separated and concentrated. The residue was then re-dissolved by small amount of acetone. Pure copolymer 2 was obtained in $83 \%$ yield by repetitive precipitation of the polymer from the acetone solution by addition of a mixture of hexanes and ethyl acetate (10:1). ${ }^{1} \mathrm{H}$ NMR (500 MHz, $\mathrm{CDCl}_{3}$ ): $\delta 4.25$ (broad, 4H), 3.50-3.84 (broad, 64H), $3.38(\mathrm{~s}, 3 \mathrm{H}), 0.95-1.35$ (broad, 15.8H), 0.85-0.95 (broad, 6.6H). PEG incorporation ratio $(r)$ is determined to be $26 \mathrm{~mol} \%$ by ${ }^{1} \mathrm{H}$ NMR. Molecular weight of hydrophobic core ( $\left.\mathrm{MW}_{\text {core }}\right)$ is $\sim 116,000 \mathrm{~g} / \mathrm{mol}$. GPC-MALS (using THF as eluent): $M_{\mathrm{n}}=463,000 \pm 2,800 \mathrm{~g} / \mathrm{mol}, M_{\mathrm{w}}=631,300 \pm$ $2,500 \mathrm{~g} / \mathrm{mol}, \mathrm{PDI}=1.4$, radius of gyration $R_{\mathrm{g}}=20.8 \pm 0.8 \mathrm{~nm}$.

SEC-MALS Characterization of the Copolymers in $\mathbf{T H F}^{7,8}$ All of the above polymers were characterized by size-exclusion chromatography (SEC) coupled to a multi-angle light scattering detector (MALS) for obtaining both the molecular weight $(M)$ and the radius of gyration $\left(R_{g}\right)$. Measurements were made on highly dilute fractions eluting from a SEC consisting of a HP Agilent 1100 solvent delivery system/auto injector with an online solvent degasser, temperaturecontrolled column compartment, and an Agilent 1100 differential refractometer. A Dawn DSP 18 -angle light scattering detector (laser wavelength $\lambda=632 \mathrm{~nm}$, Wyatt Technology, Santa Barbara, CA) was coupled to the SEC to measure both the molecular weights and sizes for each fraction of the polymer eluted from the SEC column. A $30 \mathrm{~cm}$ column was used (Polymer Laboratories PLgel Mixed C, $5 \mu \mathrm{m}$ particle size) to separate polymer samples. The mobile phase was THF and the flow rate was $0.5 \mathrm{~mL} / \mathrm{min}$. Both the column and the differential refractometer were held at 35 ${ }^{\circ} \mathrm{C}$. A $60 \mu \mathrm{L}$ of a $2 \mathrm{mg} / \mathrm{mL}$ solution was injected into the column. Software ASTRA 4.7 from Wyatt Technology was used to acquire data from the 18 scattering angle detectors and the 
differential refractometer. The $M_{\mathrm{w}}, M_{\mathrm{n}}, R_{\mathrm{g}}$ data were obtained by following classical light scattering treatments. The $R_{\mathrm{g}}$ data reported are the weight-averaged values.

Characterization of the Unimolecular Properties of Copolymer 2 in Water by Static and Dynamic Light Scattering. Both dynamic and static light scattering measurements of copolymer 2 aqueous solutions were performed at the Wyatt Technology Corporation, Santa Barbara, CA. A QELS detector was coupled to a Dawn EOS 18-angle light scattering detector (laser wavelength $\lambda=690 \mathrm{~nm}$ ) for dynamic light scattering information. The measurements were done using batch mode in pure water at $25^{\circ} \mathrm{C}$. Software ASTRA 4.90 from Wyatt Technology was used to acquire data from the 18 scattering angle detectors and QELS.

\section{Copolymer 2 only:}

Static light scattering: the weight-average radius of gyration, $R_{\mathrm{g}}$, is $17.7 \pm 4.0 \mathrm{~nm}$.

Dynamic light scattering: the average hydrodynamic radius, $R_{\mathrm{h}}$, is $26.0 \pm 0.6 \mathrm{~nm}$. Measurements for dynamic light scattering were done at copolymer 2 concentration of $1.0 \mathrm{mg} / \mathrm{mL}$.

\section{Copolymer 2 with Nile Red:}

The sample of copolymer 2 with Nile Red was prepared by adding copolymer 2 into $10 \mathrm{~mL}$ of the prepared Nile Red aqueous dispersion $(16 \mathrm{mg} / \mathrm{L})$. The mixture was sonicated for a few hours at room temperature to allow for reaching equilibrium.

Static light scattering: $R_{\mathrm{g}}$ of copolymer 2 with Nile Red encapsulated in water is $17.9 \pm 4.0 \mathrm{~nm}$. 
Dynamic light scattering: $R_{\mathrm{h}}$ of copolymer 2 with Nile Red encapsulated in water is $26.2 \pm 0.6$ $\mathrm{nm}$. Measurements for dynamic light scattering were done at copolymer 2 concentration of 1.0 $\mathrm{mg} / \mathrm{mL}$.

\section{Fluorescence and UV/vis Spectroscopic Studies of the Copolymers}

Nile Red (also known as Nile Blue A Oxazone, or NBAO) with the structure shown below was chosen as the hydrophobic dye for the encapsulation studies: ${ }^{10}$

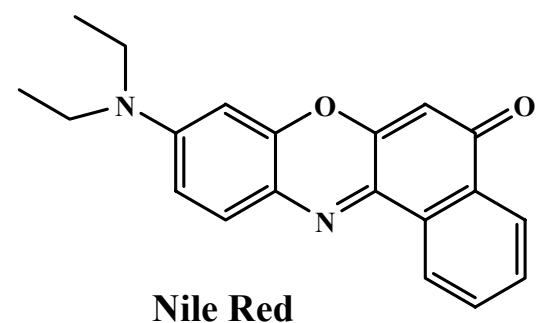

To determine the dye encapsulation capacities of the copolymers, an aqueous dispersion of Nile Red $(16 \mathrm{mg} / \mathrm{L})$ was prepared through sonication. Samples for UV/vis and fluorescence spectroscopic studies were prepared by adding copolymer $\mathbf{1}$, copolymer $\mathbf{2}$, or sodium dodecyl sulfate (SDS, 99\%, Acros) into $5 \mathrm{~mL}$ of the prepared Nile Red aqueous dispersion. The mixtures were sonicated for a few hours at room temperature to allow reaching equilibrium. After being filtered through $0.2 \mu \mathrm{m}$ hydrophilic filter (Whatman), the solutions were clear and stable for months.

All fluorescence spectra were recorded on a JASCO FP-750 fluorescence spectrophotometer, which used a 150-watt Xenon lamp with shielded lamp house as light source. Emission spectra was obtained using excitation wavelength at $570 \mathrm{~nm}$ for all of the samples. Excitation spectra was obtained using emission wavelength at $650 \mathrm{~nm}$ for all of the samples. The 
$\lambda_{\max }$ values for emission fluorescence spectra of Nile Red dye are $626 \mathrm{~nm}, 621 \mathrm{~nm}$ and $643 \mathrm{~nm}$ after addition of copolymer $\mathbf{1}$, copolymer $\mathbf{2}$ and SDS, respectively (Figure S1 and S2). The $\lambda_{\max }$ values for excitation fluorescence spectra of Nile Red dye are $556 \mathrm{~nm}, 552 \mathrm{~nm}$ and $578 \mathrm{~nm}$ after addition of copolymer 1, copolymer $\mathbf{2}$ and SDS, respectively (Figure 1).

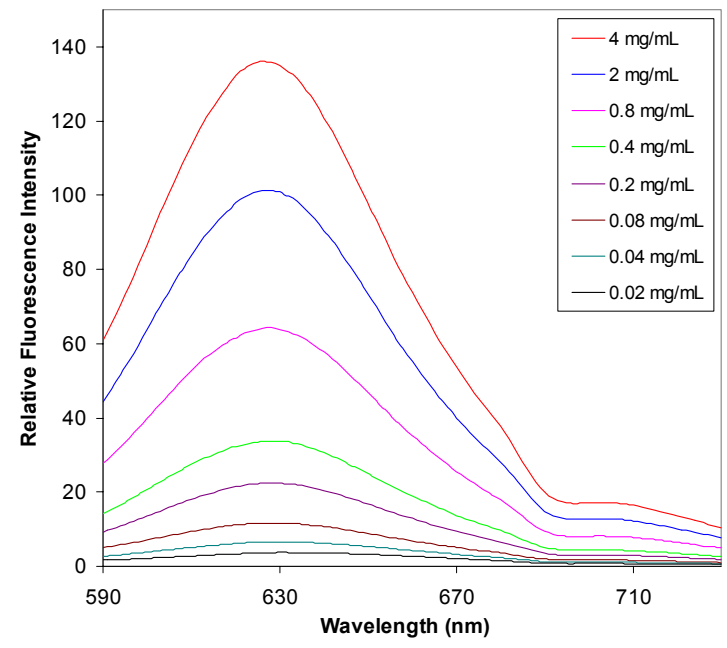

Figure S1. Fluorescence emission spectra $\left(\lambda_{\mathrm{ex}}=570 \mathrm{~nm}\right)$ of Nile Red with addition of copolymer 1 at different concentration $\left(\lambda_{\max }=626 \mathrm{~nm}\right){ }^{10}$

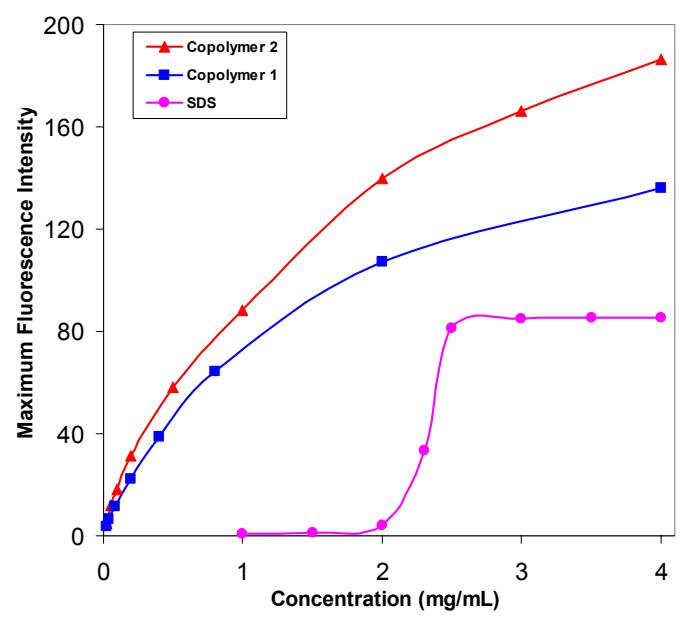

Figure S2. Fluorescence intensity at $\lambda_{\max }$ for emission spectra of Nile Red $\left(\lambda_{\mathrm{ex}}=570 \mathrm{~nm}\right)$ as a function of concentration of copolymer $\mathbf{1}$ (blue $\boldsymbol{\bullet}$ ), copolymer $\mathbf{2}\left(\right.$ red $\boldsymbol{\Delta}$ ), and SDS (purple $\bullet$ ), respectively. The $\lambda_{\max }$ is 626,621 or $643 \mathrm{~nm}$ for Copolymer 1, Copolymer 2, and SDS, respectively. 
All UV/vis spectra were recorded on a JASCO V-530 UV/vis dual-beam spectrophotometer, which used a deuterium lamp as light source for the UV range (190-350 nm) and a halogen lamp for the visible light range $(330-1100 \mathrm{~nm})$. The concentrations of Nile Red encapsulated by micelles are calculated from Beer's Law:

$$
\mathrm{A}=\varepsilon c l
$$

Where $\varepsilon$ is the molar extinction coefficiency, $c$ is the molar concentration of the encapsulated dye, and $l$ is the path length of the sample cell $(\mathrm{cm})$. The $\varepsilon$ value of Nile Red is nearly constant in most organic solvents with a value of $38,000 \mathrm{M}^{-1} \mathrm{~cm}^{-1} .{ }^{11}$ No $\varepsilon$ data is available for Nile Red in aqueous media because of its water insolubility. We chose SDS as the model system to determine the $\varepsilon$ value of Nile Red encapsulated by micelles in water. For this purpose, SDS was gradually added to a Nile Red suspension $(9.55 \mathrm{mg} / \mathrm{L}$, or $30 \mu \mathrm{M})$ until the saturation of the absorbance was observed in the resulting solutions (Figure S3a). A constant absorbance was observed at the end of the curve because all of the dye molecules were encapsulated after the saturation point. This measurement was repeated for a range of Nile Red concentrations $(3-30 \mu \mathrm{M})$. As shown in Figure S3b, maximum absorbance of these Nile Red aqueous solutions followed linear relationship with Nile Red concentration. The slop of this curve gave the $\varepsilon$ of Nile Red in aqueous micelle solutions as $38,6000 \pm 800 \mathrm{M}^{-1} \mathrm{~cm}^{-1}$. This value was used in our study of Nile Red encapsulation by SDS, copolymers 1 and $\mathbf{2}$ unimolecular micelles. 

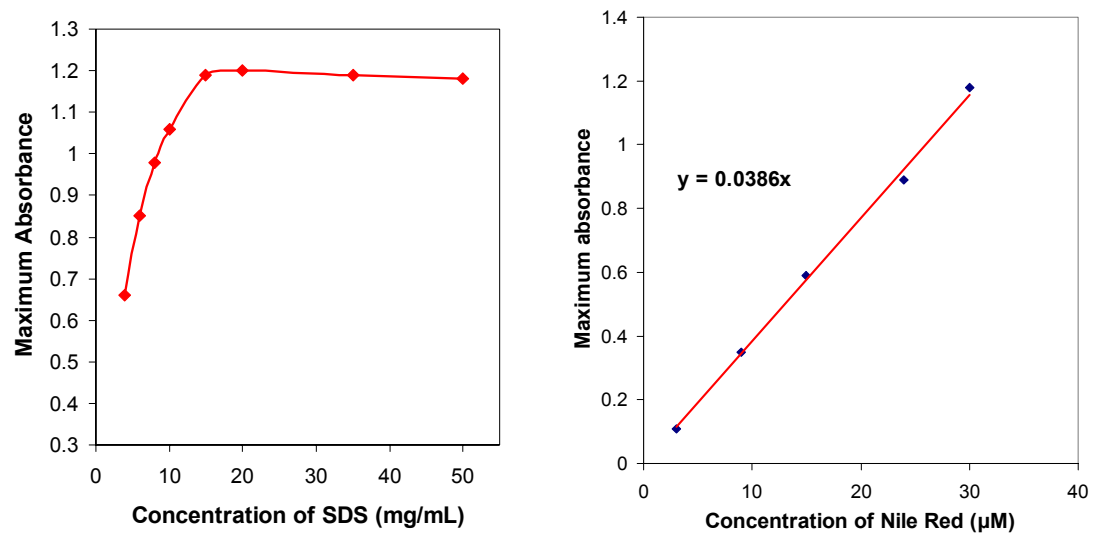

Figure S3, (a) Maximum absorbance for UV/vis spectra of Nile Red dispersion ( $30 \mu \mathrm{M})$ followed by the addition of SDS at different concentrations. (b) Maximum absorbance for UV/vis spectra of Nile Red as a function of its concentration in aqueous solutions containing SDS (SDS concentration: $30 \mathrm{mg} / \mathrm{mL}$ ).

The $\lambda_{\max }$ values for the UV/vis spectra of Nile Red dye are $554 \mathrm{~nm}, 551 \mathrm{~nm}$ and $578 \mathrm{~nm}$ after addition of copolymer 1, copolymer 2 and SDS, respectively (Figure S4, S5 and S6). The average number-of-dye per polymer molecule (dye/polymer molar ratio) was calculated from the ratio of their concentrations. The dye encapsulation capacities in weight percentage (dye/polymer weight ratio that reported in percentage) were calculated from the dye/polymer molar ratios and their molecular masses.

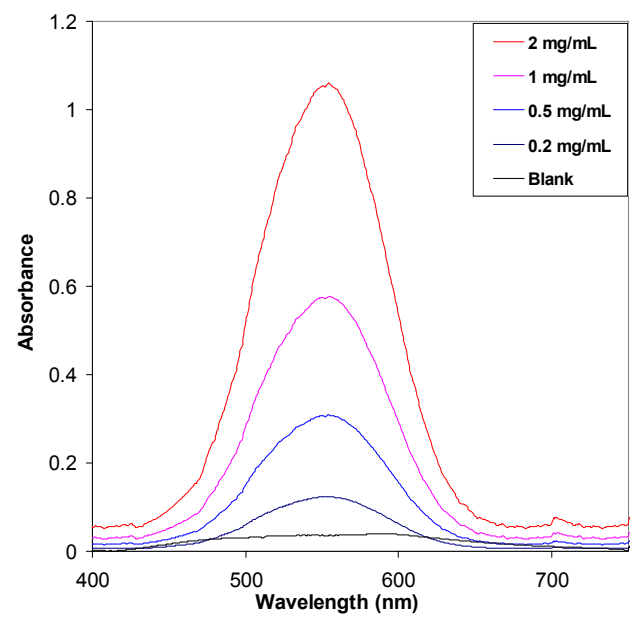

Figure S4. UV/vis spectra of Nile Red in water with different concentrations of Copolymer $1\left(\lambda_{\max }=554 \mathrm{~nm}\right)$. 


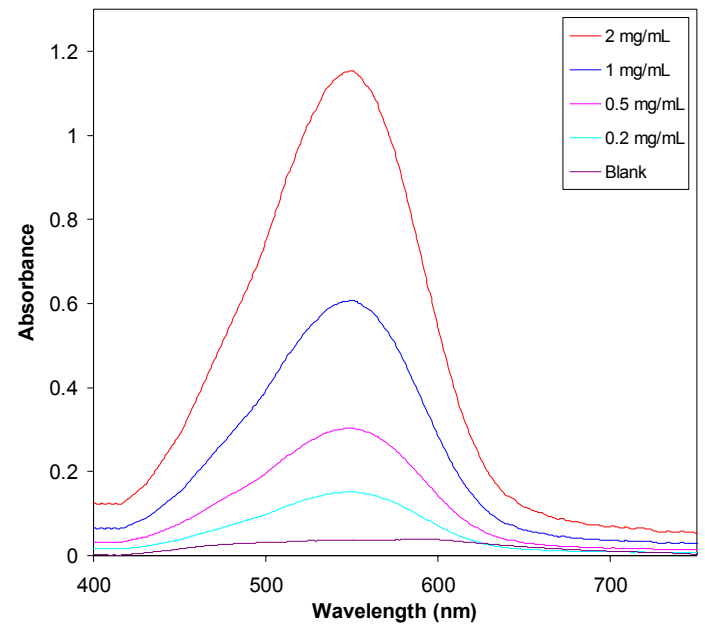

Figure S5. UV/vis spectra of Nile Red in water at different concentrations of Copolymer $2\left(\lambda_{\max }=551 \mathrm{~nm}\right)$.

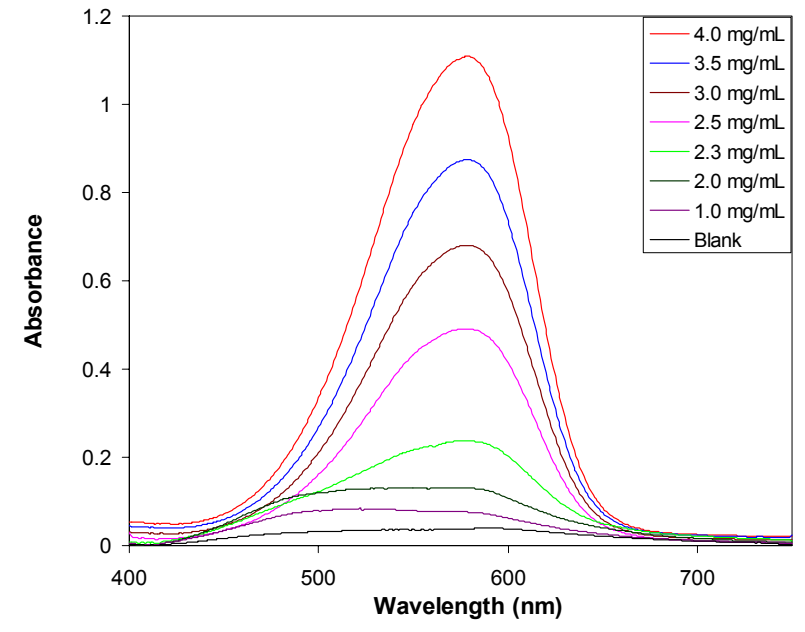

Figure S6. UV/vis spectra of Nile Red in water at different concentrations of SDS $\left(\lambda_{\max }=578 \mathrm{~nm}\right)$. 
Table S1. Quantitative Dye Encapsulation Capacity Data of Copolymers and SDS.

\begin{tabular}{|c|c|c|c|c|c|c|c|}
\hline \multicolumn{3}{|c|}{ Copolymer 1} & \multicolumn{3}{|c|}{ Copolymer 2} & \multicolumn{2}{|r|}{ SDS } \\
\hline \multirow{2}{*}{ Conc. $^{a}$} & \multicolumn{2}{|c|}{ Dye/Polymer Ratio } & \multirow{2}{*}{ Conc. ${ }^{a}$} & \multicolumn{2}{|c|}{ Dye/Polymer Ratio } & \multirow{2}{*}{ Conc. $^{\text {a }}$} & \multirow{2}{*}{$\begin{array}{c}\text { Dye/SDS Weight } \\
\text { Ratio }\end{array}$} \\
\hline & Molar Ratio & Weight Ratio $^{c}$ & & Molar Ratio & Weight Ratio $^{c}$ & & \\
\hline 0.2 & 0.156 & $0.459 \%$ & 0.2 & 8.74 & $0.525 \%$ & 2.5 & $0.077 \%$ \\
\hline 0.5 & 0.156 & $0.459 \%$ & 0.5 & 7.57 & $0.472 \%$ & 3.0 & $0.147 \%$ \\
\hline 1.0 & 0.146 & $0.429 \%$ & 1.0 & 7.28 & $0.454 \%$ & 3.5 & $0.169 \%$ \\
\hline 2.0 & 0.134 & $0.398 \%$ & 2.0 & 6.91 & $0.431 \%$ & 4.0 & $0.207 \%$ \\
\hline$A v g^{b}$ & 0.15 & $0.44 \%$ & $A v g^{b}$ & 7.6 & $0.47 \%$ & N/A & N/A \\
\hline
\end{tabular}

Note: (a): $\mathrm{mg} / \mathrm{mL}$; (b) average of values with different concentrations of copolymer $\mathbf{1}$ or copolymer 2 (not applicable to SDS); (c) dye/polymer weight ratio was reported in percentage.

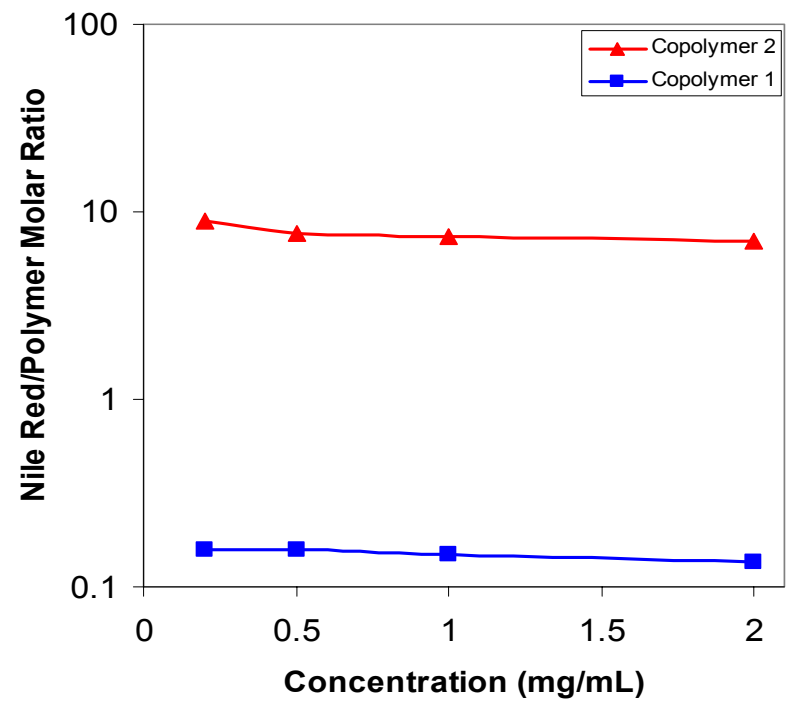

Figure S7. Number-of-dye per polymer molecule at different concentrations of copolymer 1 (blue a) and copolymer 2 (red $\mathbf{\Delta})$.

\section{References:}

(1) Pangborn, A. B.; Giardello, M. A.; Grubbs, R. H.; Rosen, R. K.; Timmers, F. J. Organometallics 1996, 15, 1518-1520.

(2) Johnson, L. K.; Mecking, S.; Brookhart, M. J. Am. Chem. Soc. 1996, 118, 267-268.

(3) Mecking, S.; Johnson, L. K.; Wang, L.; Brookhart, M. J. Am. Chem. Soc. 1998, 120, 888-899.

(4) Chen, G.; Ma, X. S.; Guan, Z. J. Am. Chem. Soc. 2003, 125, 6697-6704.

(5) Hawker, C. J.; Chu, F.; Pomery, P. J.; Hill, D. J. T. Macromolecules 1996, 29, 3831-3838.

(6) Ekwuribe, N. N.; Price, C. H.; Ansari, A. M.; Odenbaugh, A. L. In PCT Int. Appl.; (Nobex Corporation, USA). Wo, 2002, p $201 \mathrm{pp}$.

(7) Guan, Z.; Cotts, P. M.; McCord, E. F.; McLain, S. J. Science 1999, 283, 2059-2062.

(8) Cotts, P. M.; Guan, Z.; McCord, E.; McLain, S. Macromolecules 2000, 33, 6945-6952.

(9) Cser, A.; Nagy, K.; Biczok, L. Chem. Phys. Lett. 2002, 360, 473-478.

(10) Watkins, D. M.; Sayed-Sweet, Y.; Klimash, J. W.; Turro, N. J.; Tomalia, D. A. Langmuir 1997, 13, 3136-3141.

(11) Davis, Marion M.; Hetzer, Hannah B. Anal. Chem. 1966, 38, 451-461. 